\title{
REVENDO MAIS DE 70 ANOS EM MENOS DE 7 MESES: A TRAMITAÇÃO DA REFORMA TRABALHISTA DO GOVERNO TEMER
}

\author{
REVIEWING MORE THAN 70 YEARS IN LESS THAN 7 MONTHS: THE TEMER GOVERNMENT'S \\ LABOR REFORM
}

Roberto Di Benedetto ${ }^{1}$

Resumo: A reforma trabalhista do Governo Temer, aprovada no primeiro semestre de 2017, no meio de uma grave crise política e econômica, modificou profundamente o direito do trabalho, o Poder Judiciário e a estrutura sindical. A rápida tramitação da reforma, sua extensão e a ausência de um debate público dificultaram a análise dos seus impactos. Neste estudo de caso teve-se por objetivo analisar a tramitação da reforma trabalhista no Congresso e os principais argumentos utilizados pelos deputados e senadores que discutiram a proposta. Com isso, espera-se contribuir com a discussão das normas aprovadas e com a análise de suas consequências no mercado de trabalho, no Poder Judiciário e na estrutura sindical.

Palavras-chave: Reforma trabalhista. Justiça do trabalho. Estrutura sindical.

\begin{abstract}
The Temer government's labor reform, approved in the first half of 2017, in the middle of a serious political and economic crisis, changed labor law, the Judiciary, and the trade union structure. The fast reform process, its extension, and the absence of public debate made difficult to analyze its impacts. This leading case aimed to examine the process of labor reform in Congress and the main arguments used by the deputies and senators who discussed the proposal. With this, it is hoped to contribute to the discussion of the approved norms and the analysis of their consequences in the labor market, in the Judiciary and in the union structure. Keywords: Labor reform. Labor courts. Trade unions.
\end{abstract}

Doutor em Sociologia pelo Instituto de Estudos Sociais e Políticos da Universidade do Estado do Rio de Janeiro; Mestre em Direito pela Universidade Federal do Paraná; Professor Titular na Universidade Positivo; Rua Professor Pedro Viriato Parigot de Souza, 5300, Cidade Industrial, 81280-330, Curitiba, Paraná, Brasil; rdbenedetto@gmail.com 


\section{Introdução}

Neste estudo de caso tem-se por objetivo analisar a tramitação da Lei 13.467, de 13 de julho de 2017, que aprovou a reforma trabalhista do Governo Temer, e os principais argumentos utilizados pelos relatores da reforma no Congresso Nacional.

As normas que regulamentam as relações de trabalho no Brasil são o resultado de uma disputa entre o Legislativo, o Judiciário e o sistema sindical (patronal e laboral). A reforma aprovada não apenas altera as regras dos contratos individuais de trabalho, mas também pode modificar profundamente o equilíbrio de forças na disputa pela definição do direito trabalhista. Nos debates do Congresso, foi expressamente anunciada a intenção de reduzir o poder da justiça do trabalho e da estrutura sindical, em nome de uma negociação direta do trabalhador com o seu empregador.

Essa mudança não foi discutida pela sociedade. A incapacidade de reação dos atores derrotados (justiça e sindicatos) pode ser explicada, em parte, pela frenética tramitação em regime de urgência do projeto de lei aprovado em menos de sete meses nas duas casas. O objetivo com este estudo não é discutir a reforma, mas compreender a sua rápida tramitação legislativa, concentrando-se nos quatro relatórios das comissões que analisaram o projeto (uma da Câmara e três do Senado) e nos argumentos utilizados pelos relatores para impulsionar o processo legislativo e impedir a discussão aberta da reforma. Os deputados e senadores condutores da reforma não representam apenas o Congresso, mas também falam em nome do próprio Governo Temer. Por isso, o estudo destaca a tramitação e os congressistas que comandaram o processo. Além disso, o projeto aprovado é muito diferente do apresentado pelo Ministro do Trabalho, sendo a Câmara dos Deputados o principal protagonista da reforma.

Por fim, é importante salientar que, no momento da redação deste estudo (ago. 2017), ainda se aguarda a apresentação de uma prometida medida provisória que poderá alterar vários pontos da Lei aprovada. Várias centrais sindicais e sindicatos anunciam acordos com o Governo Temer para o retorno da contribuição sindical em patamares até mais elevados do que a extinta. ${ }^{2}$ Além disso, a constitucionalidade de vários dispositivos pode ser questionada judicialmente. $\bigcirc$ judiciário trabalhista tende a adotar a defesa de normas protetivas ao trabalhador como uma defesa da própria existência da justiça do trabalho. ${ }^{3}$

\footnotetext{
2 O presidente da Força Sindical, aliado de primeira hora do Governo Temer, vem anunciando a volta da contribuição no site da central sindical. O senador Cristovam Buarque (PPS-DF), que votou pela aprovação da reforma, já apresentou o Projeto de Lei n. 255, de 08 de agosto de 2017, que faz um escalonamento da extinção da contribuição sindical, além de outras mudanças na legislação trabalhista.

3 A Associação Nacional dos Magistrados da Justiça do Trabalho (Anamatra) criticou a reforma durante sua tramitação e apresentou junto à Associação Nacional dos Procuradores do Trabalho (ANPT), à Associação Brasileira dos Advogados Trabalhistas (ABRAT) e ao Sindicato Nacional dos Auditores Fiscais do Trabalho (SINAIT) uma nota técnica da Comissão de Constituição, Justiça e Cidadania do Senado alegando a inconstitucionalidade e antijuridicidade da reforma trabalhista.
} 


\section{A tramitação da reforma trabalhista de fevereiro a julho de 2017}

Três dias antes do Natal de 2016, ano em que assumiu a Presidência, Michel Temer encaminha ao Congresso Nacional um projeto de lei para alterar a CLT e a Lei 6.019/74; na ementa do projeto era dito que o objetivo da proposta seria "dispor sobre eleições de representantes dos trabalhadores no local de trabalho e sobre trabalho temporário."

O projeto foi assinado pelo Ministro do Trabalho, Ronaldo Nogueira de Oliveira, que assumiu o ministério em 12 de maio de 2016, com a suspensão do exercício do mandato da presidente Dilma, para seu julgamento perante o Senado Federal. Ronaldo Nogueira foi vereador em Carazinho em quatro legislaturas, é pastor da Igreja Evangélica Assembleia de Deus e deputado federal, desde fevereiro de 2011, ${ }^{5}$ pelo Partido Trabalhista Brasileiro (PTB/RS), sendo um dos 198 deputados que integram a Frente Parlamentar Evangélica do Congresso Nacional (CÂMARA DOS DEPUTADOS, 2015).

$O$ projeto encaminhado pelo Poder Executivo era muito mais modesto do que a Lei 13.467/17, que viria a ser aprovada. A alteração inicialmente proposta alcançava apenas sete artigos da CLT e oito artigos da Lei 6.019/1974, que tinha acabado de ser reformada pela Lei 13.429, de 31 de março de 2017, a Lei da terceirização.

A reforma trabalhista aprovada alcançou 97 artigos da CLT, cinco artigos da Lei 6.019/74, um artigo da Lei 8.036/90 e mais um artigo da Lei 8.212/91. Portanto, o texto aprovado foi muito maior e mais amplo do que o enviado originalmente pelo Ministro do Trabalho.

Em 09 de fevereiro de 2017, no retorno do recesso parlamentar, é constituída a Comissão Especial para análise do projeto na Câmara dos Deputados e, no mesmo dia, é eleito como relator o deputado Rogério Simonetti Marinho (PSDB/RN). Rogério Marinho, neto do deputado federal Djalma Aranha Marinho que atuou no Congresso de 1955 a 1979, foi vereador em Natal em duas legislaturas. Foi eleito deputado federal em 2006, pelo PSB, e eleito suplente em 2010, já pelo PSDB. Candidato à prefeito de Natal em 2012 pelo PSDB, ficou em $4^{\circ}$ lugar no $1^{\circ}$ turno. Foi novamente eleito deputado federal em 2014.

Em 10 de março, após o indeferimento pela Mesa do pedido do deputado Weverton Rocha (PDT/MA) para que a proposição fosse deliberada pelo plenário e não por uma comissão especial com poder conclusivo, é aberto o prazo para apresentação de emendas ao projeto, que foi encerrado em 22 de março. Ao todo, foram apresentadas 850 emendas que descaracterizaram a proposta inicial.

Em 12 de abril, foi apresentado o parecer do relator e o substitutivo que alterava enormemente o projeto original.

4 Mensagem n. 688, de 22 de dezembro de 2016.

5 Foi eleito suplente em 2010 e deputado em 2014 (CÂMARA DOS DEPUTADOS, 2017). 
Em 18 de abril, é aberto o prazo para apresentação de emendas ao substitutivo (até 24 de abril, foram recebidas 457 emendas) e é apresentado o requerimento de urgência que é rejeitado com 230 votos sim, 163 não e uma abstenção (394 votos).

Uma das características da 55a legislatura da Câmara dos Deputados, presidida pelos deputados Eduardo Cunha (PMDB/RJ) e Rodrigo Maia (DEM/RJ), é a submissão das decisões do parlamento à vontade do grupo político ligado ao presidente da Câmara e a habilidade desse grupo em utilizar as normas do regimento interno para impor a sua vontade e reverter derrotas. Seguindo esse padrão, no dia seguinte à derrota do requerimento de urgência, é apresentado novo requerimento de urgência, sendo este finalmente aprovado com 287 votos sim, 144 não (431 votos) e 13 obstruções (PT e PSOL). Além das manobras regimentais, o controle de uma parcela dos deputados é fundamental: de um dia para o outro, 24 deputados alteraram o seu voto e contribuíram para a aprovação da urgência rejeitada no dia anterior. ${ }^{6}$

No dia 26 de abril, o substitutivo de Rogério Marinho é aprovado pelo Plenário da Câmara dos Deputados. ${ }^{7}$ É preciso destacar que o tempo entre a apresentação do substitutivo e sua aprovação foi de apenas 14 dias!

Considerando que o projeto anterior ao substitutivo era muito diferente, que após a sua aprovação nenhuma alteração foi feita e que a discussão foi bastante cerceada, pode-se dizer que o Congresso Nacional e a sociedade brasileira tiveram acesso e possiblidade de discussão de uma das maiores reformas trabalhistas desde a criação da CLT por apenas 14 dias.

Em 28 de abril, o projeto inicia sua tramitação no Senado Federal. Na Comissão de Assuntos Econômicos (CAE) o projeto foi relatado pelo senador Ricardo de Rezende Ferraço (PSDB/ ES). Ricardo Ferraço iniciou sua trajetória política como vereador em Cachoeiro de Itapemirim, ES, em 1982. Foi duas vezes deputado estadual (1990 a 1998) e presidente da Assembleia Legislativa do Estado do Espírito Santo. Em 1998, foi eleito deputado federal pelo PPS. Vice-governador de Paulo Hartung, de 2007 a 2010, foi eleito senador em 2010.

Foram apresentadas 242 emendas ao projeto. Em 23 de maio, o relator apresenta parecer, favorável ao projeto da Câmara rejeitando todas as emendas propostas no Senado, que é aprovado por 14 votos a 11, em 06 de junho.

No dia seguinte, a Comissão de Assuntos Sociais (CAS) recebe o projeto. Em 20 de junho, o parecer favorável do senador Ricardo Ferraço é rejeitado. Com isso, é nomeado novo relator, o senador Paulo Renato Paim (PT/RS). Ex-presidente do Sindicato dos Metalúrgicos de Canoas e um

\footnotetext{
6 Votaram contra o regime de urgência em 18 de abril e favoravelmente no dia 19 os seguintes deputados: Jhonatan de Jesus (PRB/RR), Roberto Góes (PDT/AP), Arnaldo Jordy (PPS/PA), Beto Salame (PP/PA), Victor Mendes (PSD/MA), Waldir Maranhão (PP/MA), Silas Freire (PR/PI), Walter Alves (PMDB/RN), Paulo Cunha Lima (PSDB/PR), Gonzaga Patriota (PSB/PE), Kaio Maniçoba (PMDB/PE), Jony Marcos (PRB/SE), Mário Negromonte Jr. (PP/BA), Brunny (PR/MG), Tenente Lúcio (PSB/ MG), Zé Silva (Solidariedade/MG), Alexandre Serfiotis (PMDB/RJ), Ezequiel Teixeira (PODE/RJ), Hugo Leal (PSB/RJ), Luiz Carlos Ramos (PODE/RJ), Sérgio Zveiter (PMDB/RJ), Dr. Sinval Malheiros (PODE/SP), Tiririca (PR/SP) e Professor Victório Galli (PSC/MT).

7 Sim: 296; não:177; total: 473.
} 
dos fundadores da Central Única dos Trabalhadores, Paulo Paim foi deputado federal de 1987 a 2003 e está no segundo mandato de Senador (2003 a 2018).

A CAS aprovou o voto em separado do senador Paim pela rejeição integral do projeto.

Em 21 de junho, os pareceres da CAE e da CAS são encaminhados à Comissão de Constituição e Justiça (CCJ), na qual é designado o senador Romero Jucá Filho (PMDB/RR) como relator. Romero Jucá, nascido e formado em Recife, foi nomeado pelo presidente Sarney governador do Território Federal de Roraima em 1988. Em 1990, tentou ser eleito governador do recém-criado Estado, mas foi derrotado por outro ex-governador nomeado do antigo Território. É senador de Roraima desde 1995, o atual e terceiro mandato consecutivo terminará em 2018. Foi um dos principais articuladores do Governo Temer, integrando o primeiro ministério formado com a suspensão do mandato da presidente eleita. Nomeado Ministro do Planejamento, Desenvolvimento e Gestão, permaneceu no Ministério por apenas 12 dias por ter sido divulgada escuta de conversa sua com o ex-presidente da Petrobras Transporte S.A. (Transpetro), Sérgio Machado, na qual sintetizava o Governo Temer como um grande acordo da classe política e do STF para estancar as investigações e os processos iniciados com a operação lava-jato. Após a saída do ministério, voltou ao Senado para exercer a liderança do governo.

Em 28 de junho, o parecer de Romero Jucá na CCJ, favorável ao projeto oriundo da Câmara sem nenhuma alteração, foi aprovado.

Em 04 de julho, é aprovado o requerimento de urgência para o projeto de lei.

No dia marcado para a votação do projeto pelo plenário, 11 de julho, às 11h, a senadora Fátima Bezerra (PT/RN) assume a presidência da mesa junto às senadoras Vanessa Grazziotin (PCdoB/ AM), Lídice da Mata (PSB/BA) e Gleisi Hoffmann (PT/PR). Ao meio-dia, o presidente do Senado Eunício Oliveira (PMDB/CE) tenta assumir a presidência da mesa, mas como é impedido suspende a sessão. Durante toda a tarde, as senadoras permanecem ocupando a mesa, o presidente do Senado determinou o desligamento do sistema de som, da iluminação do plenário e da transmissão da TV Senado. Às 18h34, Eunício Oliveira reabre a sessão utilizando um microfone sem fio e com a mesa ocupada. A votação é encaminhada sem sistema de som no plenário e com grande tumulto. Às $22 \mathrm{~h} 20$, a sessão é encerrada com a aprovação do projeto que veio da Câmara sem nenhuma alteração. ${ }^{8}$

\footnotetext{
8 O projeto foi aprovado por 50 votos contra 26 e uma abstenção.

Votaram pela aprovação do projeto: Aécio Neves (PSDB-MG), Airton Sandoval (PMDB-SP), Ana Amélia (PP-RS), Antonio Anastasia (PSDB-MG), Armando Monteiro (PTB-PE), Ataídes Oliveira (PSDB-TO), Benedito de Lira (PP-AL), Cássio Cunha Lima (PSDB-PB), Cidinho Santos (PR-MT), Ciro Nogueira (PP-PI), Cristovam Buarque (PPS-DF), Dalirio Beber (PSDB-SC), Dário Berger (PMDB-SC), Davi Alcolumbre (DEM-AP), Edison Lobão (PMDB-MA), Eduardo Lopes (PRB-RJ), Elmano Férrer (PMDB-PI), Fernando Bezerra Coelho (PSB-PE), Flexa Ribeiro (PSDB-PA), Garibaldi Alves (PMDB-RN), Gladson Cameli (PP-AC), Ivo Cassol (PP-RO), Jader Barbalho (PMDB-PA), João Alberto Souza (PMDB-MA), José Agripino Maia (DEM-RN), José Maranhão (PMDB-PB), José Medeiros (PSD-MT), José Serra (PSDB-SP), Lasier Martins (PSD-RS), Magno Malta (PR-ES), Marta Suplicy (PMDB-SP), Omar Aziz (PSD-AM), Paulo Bauer (PSDB-SC), Pedro Chaves (PSC-MS), Raimundo Lira (PMDB-PB), Ricardo Ferraço (PSDB-ES), Roberto Muniz (PP-BA), Roberto Rocha (PSB-MA), Romero Jucá (PMDB-RR), Ronaldo Caiado (DEM-GO), Rose de Freitas (PMDB-ES), Sérgio Petecão (PSD-AC), Simone Tebet (PMDB-MS), Tasso Jereissati (PSDB-CE), Valdir Raupp (PMDB-RO), Vicentinho Alves (PR-TO), Waldemir Moka (PMDB-MS), Wellington Fagundes (PR-MT), Wilder Morais (PP-GO), Zeze Perrella (PMDB-MG).

Votaram contra o projeto: Álvaro Dias (Pode-PR), Ângela Portela (PDT-RR), , Antonio Carlos Valadares (PSB-SE), Eduardo Amorim (PSDB-SE), Eduardo Braga (PMDB-AM), Fátima Bezerra (PT-RN), Fernando Collor (PTC-AL), Gleisi Hoffmann (PT-PR), Humberto Costa (PT-PE), João Capiberibe (PSB-AP), Jorge Viana (PT-AC), José Pimentel (PT-CE), Kátia Abreu
} 
Em parte, essa aprovação foi obtida pela promessa do relator, Ricardo Ferraço, e do líder do Governo, Romero Jucá, de que haveria vetos presidenciais ao projeto e que seria editada Medida Provisória modificando vários pontos da reforma.

O presidente Temer sanciona o projeto, sem nenhum veto, em 13 de julho.

Até o momento, 20 de agosto, não foi apresentada nenhuma Medida Provisória.

\section{As alterações na legislação trabalhista e as razões apresentadas pelos relatores no Congresso Nacional}

É possível reunir as alterações realizadas na legislação trabalhista e as razões de fundamentação apresentadas pelos relatores no Congresso Nacional em três grupos: a redução do poder da Justiça do Trabalho e a limitação do acesso aos sistemas de justiça; a precarização dos contratos de trabalho e a redução do custo com a mão de obra; e o enfraquecimento da estrutura sindical.

\subsection{Justiça do Trabalho e acesso aos sistemas de justiça}

A análise dos sistemas de proteção do trabalho costuma classificar os ordenamentos nacionais em sistemas legislados ou sistemas negociados. O Brasil, em tese, adotaria um sistema legislado, mas a história e a forma de atuação da nossa proteção trabalhista permitem falar de um sistema judicializado de regulação das relações de trabalho. As normas jurídicas legisladas são dosadas e modificadas por um complexo sistema de decisões judiciais e um inigualável conjunto de direito sumular.

No direito e na justiça trabalhista, o direito sumular ocupa uma posição central. Nenhum outro ramo do Judiciário é tão protagonista na alteração, modificação e adaptação do direito a partir de súmulas, orientações jurisprudenciais, precedentes normativos, teses jurídicas prevalecentes, instruções normativas e resoluções.

As súmulas não somente fixam a forma como o tribunal interpreta o direito do trabalho, mas também inovam a ordem jurídica, criam direito novo. Portanto, mudanças sumulares não são apenas mudanças de interpretações do TST e dos Regionais, são mudanças do próprio direito do trabalho. Assim como os membros do Legislativo recebem as mais variadas influências e pressões no processo de criação de leis, os ministros e os desembargadores também refletem o contexto político, econômico e social na definição do direito do trabalho por meio da edição de enunciados jurisprudenciais.

(PMDB-TO), Lídice da Mata (PSB-BA), Lindbergh Farias (PT-RJ), Otto Alencar (PSD-BA), Paulo Paim (PT-RS), Paulo Rocha (PT-PA), Randolfe Rodrigues (Rede-AP), Regina Sousa (PT-PI), Reguffe (sem partido-DF), Renan Calheiros (PMDB-AL), Roberto Requião (PMDB-PR), Romário (Pode-RJ), Telmário Mota (PTB-RR), Vanessa Grazziotin (PC do B-AM).

Absteve-se: Lúcia Vânia (PSB-GO). 
Apenas na década de 1960 os tribunais superiores no Brasil passaram a sistematizar as suas decisões por meio de súmulas da jurisprudência. A súmula surge no ordenamento jurídico brasileiro com a Emenda ao Regimento Interno do Supremo Tribunal Federal, de agosto de 1963, patrocinada pelo ministro Victor Nunes Leal.

As primeiras súmulas do TST aparecem em agosto de 1969. Em meados da década de 1990 passaram a ser editadas as Orientações Jurisprudenciais das Subseções Especializadas em Dissídios Individuais e da Seção de Dissídios Coletivos, além dos Precedentes Normativos. Em agosto de 2017, existiam 463 Súmulas da Jurisprudência Uniforme do Tribunal Superior do Trabalho, 13 Orientações Jurisprudenciais do Órgão Especial e do Tribunal Pleno (OJ-TP e OJ-TP/OE), 421 Orientações Jurisprudenciais da Subseção I Especializada em Dissídios Individuais (OJ-SDI1), 79 Orientações Jurisprudenciais Transitórias da Subseção I Especializada em Dissídios Individuais (OJ-SDI1T), 158 Orientações Jurisprudenciais da Subseção II Especializada em Dissídios Individuais (OJ-SDI2), 38 Orientações Jurisprudenciais da Seção de Dissídios Coletivos (OJ-SDC) e 120 Precedentes Normativos (PN). O que totalizou 1.292 enunciados do entendimento do TST a respeito da melhor forma de interpretar e aplicar a legislação trabalhista.

Nenhum outro tribunal tem algo parecido. OSTJ, maior tribunal superior brasileiro, responsável por uniformizar a interpretação da lei federal em todo o Brasil, tem 586 súmulas. Para uniformizar o entendimento de toda a legislação federal o STJ usa menos da metade dos enunciados do TST. O STF, nossa Corte Constitucional, tem 736 súmulas e 56 súmulas vinculantes.

O número de súmulas nos Regionais não é nada modesto, mas é preciso destacar que grande parte desse processo de criação de súmulas nos regionais ocorreu na última década. O TRT2 começou a editar súmulas somente em 2002 e, em agosto de 2017, contava com 79 súmulas, 20 OJs, 41 PNs e 25 Teses Jurídicas Prevalecentes (TJP). O TRT15 editou 105 súmulas, 70 PNs, 42 OJs e cinco Teses Prevalecentes, a partir de 1997. O TRT3 acumula, a partir de 2000, 63 súmulas, 46 OJs, 219 PNs e 15 TJPs. O TRT4 foi o primeiro dos cinco grandes a criar súmulas, desde 1992, e hoje soma o maior número, 119 súmulas, 75 Precedentes, 81 OJs e seis TJPs. O TRT da $1^{a}$ Região foi o último a criar súmulas, apenas em 2009, e tem 61 súmulas e oito TJPs. A soma dos enunciados dos cinco maiores regionais chega a 1.080 entendimentos jurisprudenciais.

Além disso, o TST vem criando normas processuais por meio de Instruções Normativas (IN) aprovadas por Resoluções. O Regimento Interno do Tribunal é bastante lacônico sobre essa forma de criação normativa, limita-se a regular as Resoluções já no título das disposições finais. Entretanto, a modesta regulamentação não é proporcional à importância das Instruções Normativas dos TST. Para citar apenas alguns exemplos, a Instrução Normativa 16, de 26 de agosto de 1999 (alterada em maio de 2003), regulou o Agravo de Instrumento na Justiça do Trabalho. Ora, a Constituição da República é bastante clara ao dizer que a competência para legislar em matéria processual é privativa da União, portanto, do Congresso Nacional por meio de Lei. O TST, com a desculpa de que está uniformizando a interpretação da Lei, cria regras próprias para um dos recursos mais utilizados no 
processo trabalhista. Seguindo essa linha, as Instruções Normativas 17, de 17 de dezembro de 1999, e 23, de 05 de agosto de 2003, disciplinaram o Recurso de Revista. A IN 27, de 16 de fevereiro de 2005, criou normas processuais para os novos casos advindos da ampliação da competência da Justiça do Trabalho.

Vê-se, portanto, que os magistrados trabalhistas estão muito longe do entendimento de que o direito provém da Lei do parlamento, eles mesmos podem criar o direito seja por jurisprudência (súmula, OJ, PN, TJP), seja por decisão do Tribunal fora de qualquer ação judicial proposta por indivíduos ou instituições.

É justamente esse ponto que é atacado pela reforma trabalhista. $\bigcirc \$ 2^{\circ}$ incluído no art. $8^{\circ}$ da CLT determina que: "súmulas e outros enunciados de jurisprudência editados pelo Tribunal Superior do Trabalho e pelos Tribunais Regionais do Trabalho não poderão restringir direitos legalmente previstos nem criar obrigações que não estejam previstas em lei."

Além de limitar o alcance dos enunciados de jurisprudência dos tribunais trabalhistas, a reforma interfere no processo de criação desses enunciados com a inclusão da alínea f, no inciso I, do art. 702:

f) estabelecer ou alterar súmulas e outros enunciados de jurisprudência uniforme, pelo voto de pelo menos dois terços de seus membros, caso a mesma matéria já tenha sido decidida de forma idêntica por unanimidade em, no mínimo, dois terços das turmas em pelo menos dez sessões diferentes em cada uma delas, podendo, ainda, por maioria de dois terços de seus membros, restringir os efeitos daquela declaração ou decidir que ela só tenha eficácia a partir de sua publicação no Diário Oficial;

E a inclusão dos $\iint 3^{\circ}$ e $4^{\circ}$ neste mesmo artigo:

$\int 3^{\circ}$ As sessões de julgamento sobre estabelecimento ou alteração de súmulas e outros enunciados de jurisprudência deverão ser públicas, divulgadas com, no mínimo, trinta dias de antecedência, e deverão possibilitar a sustentação oral pelo Procurador-Geral do Trabalho, pelo Conselho Federal da Ordem dos Advogados do Brasil, pelo Advogado-Geral da União e por confederações sindicais ou entidades de classe de âmbito nacional.

$\int 4^{\circ} \mathrm{O}$ estabelecimento ou a alteração de súmulas e outros enunciados de jurisprudência pelos Tribunais Regionais do Trabalho deverão observar o disposto na alínea $f$ do inciso I e no $\mathbb{3} 3^{\circ}$ deste artigo, com rol equivalente de legitimados para sustentação oral, observada a abrangência de sua circunscrição judiciária.

É evidente que a aplicação desses novos dispositivos poderá alterar profundamente toda a forma de funcionamento da Justiça do Trabalho no Brasil. O deputado Rogério Marinho deixa essa intenção bastante expressa em seu relatório:

Os tribunais em nosso País, em especial, as cortes trabalhistas, têm se utilizado da edição de súmulas e de outros enunciados de jurisprudência para legislar, adotando, algumas vezes, até mesmo um entendimento contrário à norma vigente. Com a nova redação proposta para o art. $8^{\mathbf{o}}$, queremos deixar evidente a supremacia da lei na aplicação do Direito do Trabalho, por mais paradoxo que possa parecer tal dispositivo, impedindo-se, dessa forma, a inversão da ordem de aplicação 
das normas. Essa prática tem dado margem à um aumento no número de ações ajuizadas perante a Justiça do Trabalho, pois é comum que o empregador, mesmo cumprindo toda a legislação e pagando todas as verbas trabalhistas devidas, se veja demandado em juízo com pedidos fundados apenas em jurisprudências e súmulas dos tribunais. (MARINHO, 2017, p. 32-33).

O argumento de limitar o poder da Justiça do Trabalho e alterar entendimentos sumulados aparece em várias partes do relatório da Comissão Especial da Câmara. Desde a sua apresentação:

Ocorre, porém, que temos visto com frequência os tribunais trabalhistas extrapolarem sua função de interpretar a lei por intermédio de súmulas, para, indo além, decidirem contra a lei. Assim, um instrumento que deveria ter a finalidade precípua de trazer segurança jurídica ao jurisdicionado, garantindo a previsibilidade das decisões, é utilizado, algumas vezes, em sentido diametralmente oposto, desconsiderando texto expresso de lei. (MARINHO, 2017, p. 23).

No comentário de cada dispositivo alterado na CLT para derrubar uma súmula ou orientação jurisprudencial, o relator volta ao tema do excesso de poder da justiça do trabalho. Isso vai ocorrer expressamente na explicação de seis alterações da reforma.

$\mathrm{Na}$ explicação do art. 11-A que regula a prescrição intercorrente no processo do trabalho: "Mas, no Brasil, o crédito trabalhista não prescreve, segundo Súmula do TST, que contraria frontalmente Súmula sobre tema idêntico do STF." (MARINHO, 2017, p. 35).

$\mathrm{Na}$ apresentação da alteração do $\int 4^{\circ}$ do art. 71 , que regula o intervalo para repouso e alimentação:

Porém, se o trabalhador usufruir de apenas trinta minutos desse intervalo, o TST, nos termos da Súmula 437, entende que o intervalo restante, de trinta minutos, gera uma condenação de 1 hora e 30 minutos, e ainda com adicional de $50 \%$, e reflexos em férias com $1 / 3,13^{\circ}$ salário, base de cálculo ainda para recolhimento de FGTS, INSS, e outros adicionais, como o adicional noturno e de insalubridade, por exemplo. Ou seja, os acréscimos que deveriam incidir sobre meia hora, são calculados sobre uma hora e meia.

É importante ressaltar que a Súmula 437 do TST não possui respaldo na Constituição ou mesmo na legislação, sendo um exemplo claro de ativismo judicial que criou obrigações sem lei que a exija e que invade a esfera do Poder Legislativo. (MARINHO, 2017, p. 43, grifo nosso).

Na inclusão do $₫ 2^{\circ}$ no art. 468, feita exclusivamente para derrubar a Súmula 372 do TST 9 e, segundo o deputado tucano, devolver o poder de comando na direção da empresa ao empregador: "o TST, por intermédio de súmula de jurisprudência, tem entendido que, se o empregado tiver

\footnotetext{
9 Súmula 372 GRATIFICAÇÃO DE FUNÇÃO. SUPRESSÃO OU REDUÇÃO. LIMITES (conversão das OJs nº 45 e 303 da SBDI-I) - Res. 129/2005, DJ 20, 22 e 25.04.2005

I - Percebida a gratificação de função por dez ou mais anos pelo em- pregado, se o empregador, sem justo motivo, revertê-lo a seu cargo efetivo, não poderá $\square$ retirar-lhe a gratificação tendo em vista o princípio da estabilidade financeira. (ex-OJ n ${ }^{\circ} 45$ da SBDI-I - inserida em 25.11.1996)

II - Mantido o empregado no exercício da função comissionada, não pode o empregador reduzir o valor da gratificação. (ex-OJ n 303 da SBDI-I - DJ 11.08.2003)
} 
passado mais de dez anos no exercício da função, a gratificação respectiva deverá ser incorporada à remuneração mesmo se houver a reversão ao cargo efetivo." (MARINHO, 2017, p. 53).

Assim como a alteração do $\int 3^{\circ}$, que tem como objetivo encerrar uma disputa judicial entre o TST e o STF em torno da Súmula $277^{10}$ do TST:

A nova redação proposta ao $₫ 3^{\circ}$ do art. 614 também intenta garantir maior segurança jurídica às partes da relação empregatícia, uma vez que os tribunais trabalhistas têm, reiteradamente, decidido contra a lei em relação ao tema aqui proposto.

$O \lessgtr 3^{\circ}$ do art. 614 da CLT, em sua redação vigente, determina que os instrumentos de negociação coletiva não poderão ter prazo de vigência superior a dois anos. No entanto o TST decidiu por súmula que as cláusulas negociadas entre as partes se incorporam ao contrato individual de trabalho mesmo após o fim do prazo estipulado no acordo coletivo ou na convenção coletiva, vigorando até que novo instrumento seja celebrado. É o que se chama princípio da ultratividade da norma. O STF, provocado, decidiu pela suspensão liminar de todos os processos, bem como dos efeitos, de decisões no âmbito da Justiça do Trabalho que discutam a aplicação da ultratividade de normas coletivas de trabalho. (MARINHO, 2017, p. 61).

Todos esses argumentos contra a atuação dos tribunais trabalhistas são reforçados na análise da alteração do art. 702, que altera a forma de elaboração de súmulas, quando o deputado Rogério Marinho é novamente bastante explícito ao afirmar que:

As mudanças sugeridas em relação ao art. 702 baseiam-se no já mencionado ativismo judicial frequentemente praticado pelos tribunais trabalhistas.

São inúmeras as decisões contidas em enunciados de jurisprudência do TST que interpretam além do que prevê a lei, ou até mesmo contra a lei, em muitos casos, das quais podemos suscitar como exemplos o pagamento integral do intervalo intrajornada gozado apenas parcialmente (Súmula no 437), a já citada ultratividade das normas coletivas (Súmula no 277), a estabilidade provisória de empregada gestante em contrato de trabalho por tempo determinado (Súmula no 244), pagamento em dobro das férias fracionadas irregularmente e cumulação dos adicionais de insalubridade e de periculosidade (Precedentes do TST), entre tantos outros.

Assim, com a redação dada ao art. 702 da CLT, pretendemos limitar as interpretações ampliativas, e em alguns casos criativas, por parte do TST. As sugestões pretendem implementar requisitos mínimos para a edição de súmulas e outros enunciados de jurisprudência, tomando por base procedimentos já previstos no Código de Processo Civil e para o STF. (MARINHO, 2017, p. 64-65, grifo nosso).

A reforma do art. 843 também é feita para revogar a Súmula $377^{11}$ do TST:

\footnotetext{
10 Súmula 277 CONVENÇÃO COLETIVA DE TRABALHO OU ACORDO COLETIVO DE TRABALHO. EFICÁCIA. ULTRATIVIDADE (redação alterada na sessão do Tribunal Pleno realizada em 14.09.2012) - Res. 185/2012 - DEJT divulgado em 25,26 e 27.09 .2012

As cláusulas normativas dos acordos coletivos ou convenções coletivas integram os contratos individuais de trabalho e somente poderão ser modificadas ou suprimidas mediante negociação coletiva de trabalho.

11 Súmula 377 PREPOSTO. EXIGÊNCIA DA CONDIÇÃO DE EMPREGADO - Res. 146/2008, DJ 28.04.2008, 02 e 05.05 .2008 Exceto quanto à reclamação de empregado doméstico, ou contra micro ou pequeno empresário, o preposto deve ser necessariamente em- pregado do reclamado. Inteligência do art. 843, $\mathbb{S} 1^{\circ}$, da CLT e do art. 54 da Lei Complementar no 123 , de 14 de dezembro de 2006.
} 
A interpretação dada à matéria pelo TST, por intermédio da Súmula n 377 , é a de que, com exceção de reclamação de empregado doméstico ou contra micro ou pequeno empresário, o preposto deve ser necessariamente empregado do reclamado. Essa exigência não nos parece razoável, uma vez que o fundamental na questão é que o preposto tenha conhecimento dos fatos tratados na reclamatória, independentemente de ser empregado ou não, já que, no cumprimento desse mandato, os atos praticados pelo preposto comprometerão o empregador. (MARINHO, 2017, p. 71-72).

Toda essa arguição contra o judiciário trabalhista está alinhada com a discussão que ocorrerá na sequência no Senado Federal. Na Comissão de Assuntos Econômicos, o relator senador Ricardo Ferraço (PSDB/ES) utilizará os ministros do Supremo Roberto Barroso e Gilmar Mendes para atacar o ramo trabalhista e pedir a limitação desse poder; uma das sessões do relatório é intitulada Populismo judicial, e a longa transcrição a seguir tem o objetivo de ressaltar a construção das teses contra o judiciário feita pelo senador capixaba:

[...] já falamos diversas vezes neste relatório sobre o problema do populismo, do ativismo judicial. Ele se caracteriza pela infame invasão das competências do Congresso Nacional; pela insegurança jurídica que inibe a criação de empregos; e por decisões impensadas que em seu conjunto acabam por prejudicar o trabalhador. Alguns exemplos já foram dados aqui, como a questão das horas in itinere ou da redução do intervalo intrajornada, que punem os brasileiros privando-lhes de melhores possibilidades de deslocamento até o trabalho e da oportunidade de voltar mais cedo do serviço para casa.

$[\ldots]$

Na preliminar de constitucionalidade, salientamos como insistentemente a Justiça Trabalhista, liderada pelo TST, adentra em nossas competências e afronta princípios constitucionais como o da legalidade, previsto no próprio caput do art. $5^{\circ}$ da Carta Magna, o da separação dos Poderes, previsto nos arts. $2^{\circ}$ e 60 da Constituição, e o da conformidade funcional. [...]

Este é um dos princípios constitucionais que a Justiça do Trabalho, enquanto intérprete da Constituição, tem violado de maneira serial. Ressaltemos mais uma vez o que já observamos antes: este ativismo já foi reconhecido, e criticado, sucessivas vezes pelo próprio Supremo Tribunal Federal (STF).

$O$ atual desenho do processo trabalhista, combinado com este ativismo, gera o inacreditável cenário atual. Segundo o Ministro da Suprema Corte Luís Roberto Barroso, em declaração recente, o país é responsável por $98 \%$ das ações trabalhistas do planeta, tendo apenas $3 \%$ da população mundial. Todos os anos, produzimos mais ações judiciais na área do que a soma de outros países. Provoco uma reflexão: somos tão especiais assim? O mundo está errado? (FERRAÇO, 2017, p. 55-56).

Esse último parágrafo revela muito do espírito da reforma aprovada, não existe nenhum pudor no senador em utilizar um dado evidentemente falso. A utilização do argumento de autoridade do Ministro Barroso não tem o condão de transformar um absurdo em verdade. Após a aberração dos $98 \%$ das ações trabalhistas do mundo, o relatório do senador Ferraço segue com o tópico Ativismo e segurança jurídica, e mais uma vez a longa citação é importante para revelar a disputa aberta entre os poderes:

Um primeiro grupo de medidas da reforma trabalhista em relação ao ativismo judicial está na redação dada ao art. $8^{\circ}$ da CLT, que deveria ser senso comum. Nos $\mathbb{S} \int 1^{\circ}$ a $3^{\circ}$ do dispositivo, conforme a redação do PLC, fica expresso que a fonte 
subsidiária do direito do trabalho é o direito comum; que súmulas e outros enunciados do TST e dos TRT não podem restringir direitos nem criar obrigações que não tenham sido aprovadas pelo Congresso Nacional por meio de lei; e que nas negociações coletivas a Justiça do Trabalho deve analisar apenas a conformidade dos elementos essenciais, se pautando pelo princípio da intervenção mínima na autonomia da vontade coletiva.

Sem essa previsão, temos hoje situações que já exploramos neste texto, como o intervalo intrajornada não usufruído em 15 minutos ser indenizado como se de 1 hora fosse, ou a anulação de negociações coletivas porque um magistrado julga que sabe mais do que o trabalhador o que é melhor para ele próprio.

Não prospera o argumento contrário ao PLC de que ele viola o "princípio da inafastabilidade do controle judicial" consubstanciado no art. $5^{\circ}$, inciso XXXV da Carta Magna, que preconiza que "a lei não excluirá da apreciação do Poder Judiciário lesão ou ameaça a direito". Relembremos: conforme o art. 22, inciso I, da Constituição é ao Congresso Nacional quem compete legislar sobre direito do trabalho, e, conforme o art. 24, inciso I, é competência da União estabelecer normas gerais de direito econômico.

Desta forma, cabe ao Congresso Nacional e, sobretudo, às próprias categorias no âmbito da negociação coletiva, criarem direitos e obrigações, e não ao Judiciário. Embora a interpretação e aplicação das normas não seja uma atividade mecânica, não há dúvida de que cabe ao Judiciário assegurar que os deveres e obrigações existentes por força de lei ou negociação coletiva sejam cumpridos, e não inovar na ordem jurídica para criar novos direitos e obrigações.

Oportuno salientar que muitas danosas decisões judiciais invocam não a lei, mas princípios ou teorias, como a chamada "teoria da subordinação estrutural", para inovar na ordem jurídica. Há uma profusão de ações reconhecendo vínculos empregatícios e responsabilidades trabalhistas entre empregados de uma empresa $\mathrm{A}$ e o empregador de uma empresa B, meramente porque B e A pertencem a uma mesma cadeia produtiva. Há previsão legal para essas condenações? Não. Isto impede que os juízes criem normas, à revelia do Congresso? Também não.

$[\ldots]$

É fundamental observar aqui que o objetivo da proposta não é proteger empresas ou considerá-las hipossuficientes. É proteger a pessoa, tanto as incluídas, as empregadas com carteira assinada, quanto as excluídas: as desempregadas, as informais, as desalentadas. São elas que são penalizadas pela insegurança jurídica que inibe a criação de empregos, e não os patrões. (FERRAÇO, 2017, p. 56-57, grifo nosso).

Desse modo, a reforma trabalhista mudou entendimentos sumulados e impediu novas súmulas inovadoras da ordem jurídica. Mas, além disso, algumas novidades incluídas têm por objetivo impedir que algumas demandas alcancem o Poder Judiciário. Fechando-se o ciclo de fragilização do sistema de proteção atual, além de mudar o entendimento dos tribunais e impedir o desenvolvimento de interpretações protetivas, afastam-se de sua apreciação determinadas questões. Exemplos disso são: a aplicação da arbitragem ao direito do trabalho (art. 507-A), ${ }^{12}$ o acordo extrajudicial (arts. 855-B a 855-E), o termo de quitação anual de obrigações trabalhistas (art. 507-B) e a eficácia de instrumento coletivo para a negociação do empregado com curso superior e salário igual ou maior a R $\$$ 11.062,62 (art. 444, parágrafo único).

\footnotetext{
12 O art. $1^{\circ}$ da lei da arbitragem, Lei 9.307/96, prescreve: "As pessoas capazes de contratar poderão valer-se da arbitragem para dirimir litígios relativos a direitos patrimoniais disponíveis." Portanto, para os autores da reforma trabalhista, o direito do trabalho deixou de ser um direito social e passou para a categoria de direito patrimonial disponível.
} 


\subsection{Precarização das relações trabalhistas}

A limitação prévia do poder da justiça trabalhista é condição para a precarização das relações de trabalho pretendida pela reforma. É claro para os autores, que contaram inclusive com a consultoria de alguns juízes, que de nada adiantaria criar modalidades flexíveis de contração se o judiciário pudesse, na sequência, criar limitações para essa "modernização" proposta.

Resolvido o primeiro problema, a reforma passa a criar um amplo cardápio de relações flexíveis e "modernas": ampliação do regime de tempo parcial para até 32 horas; inclusão da jornada 12 por 36 na CLT, com a retirada de limitações fixadas pela jurisprudência do TST; contratação de trabalhadores autônomos; contrato de trabalho intermitente; terceirização ampla, geral e irrestrita; teletrabalho; e trabalho insalubre da gestante e lactante.

\subsubsection{Regime de tempo parcial}

$\mathrm{O}$ art. 58-A, que regula o trabalho em regime de tempo parcial, foi incluído na CLT pela Medida Provisória 2.164-41, de 24 de agosto de 2001. Esse é um dispositivo bastante curioso, trata-se de uma das reformas trabalhistas do Governo FHC, feita pelo poderoso instrumento das MPV reeditáveis. Essa Medida Provisória nasceu como MPV 1.709, de 06 de agosto de 1998, que foi substituída pela MPV 1.779-5, de 14 de dezembro de 1998, revogada e reeditada pela MPV 1.879-12, de 29 de junho de 1999, trocada pela MPV 1.952-18, de 09 de dezembro de 1999, também por sua vez revogada e reeditada pela MPV 2.076-32, de 27 de dezembro de 2000, que, revogada e reeditada pela MPV 2.164-39, de 28 de junho de 2001, é finalmente substituída pela MPV 2.164-40, de 27 de julho 2001. Com a Emenda Constitucional 32, a versão 41 dessa Medida Provisória de três anos adquiriu vida eterna e continua no ordenamento até hoje.

Agora, a reforma trabalhista do Governo Temer encontra a reforma trabalhista do Governo FHC, e o artigo da Medida Provisória é reformado por uma Lei aprovada de maneira açodada para ampliar a precarização dos anos 1990.

O regime de tempo parcial, antes limitado ao máximo de 25 horas, poderá ter agora até 30 horas semanais ou 26 horas com até 6 horas extras.

Um contrato de tempo parcial de 32 horas funcionará como uma redução salarial, dificilmente o empregado que trabalhava 44 horas conseguirá outro trabalho formal, nas 12 horas reduzidas, ainda mais em um cenário econômico de recessão. Há poucos anos, os sindicatos organizaram manifestações para a redução da jornada semanal em quarenta horas com a manutenção dos salários. Agora, a mudança do regime de tempo parcial proporcionará a redução dos salários com a redução da jornada. 


\subsubsection{Jornada 12 por 36}

A jornada de 12 horas de trabalho por 36 horas de descanso era regulada de forma restrita pela Súmula 444 do TST ${ }^{13}$ e pela OJ-SDI1 388. ${ }^{14}$ Ela tinha caráter excepcional, exigia convenção coletiva ou acordo coletivo, remunerava em dobro os feriados trabalhados e garantia o direito ao adicional noturno para as horas trabalhadas após às cinco horas da manhã quando trabalhada a totalidade do período noturno.

O art. 59- $\mathrm{A}^{15}$ inclui na CLT a jornada 12 por 36, mas amplia em muito a sua possibilidade de aplicação. A reforma retira o caráter de excepcionalidade, permite a adoção por acordo individual, além do acordo coletivo ou convenção coletiva e elimina a remuneração em dobro dos feriados e a remuneração da prorrogação do trabalho noturno.

\subsubsection{Contratação de autônomo}

Durante décadas discutiu-se no Brasil a terceirização e a pejotização. A reforma trabalhista do Governo Temer mudou completamente a discussão. O singelo e lacônico art. 442-B permite uma flexibilidade inimaginável nas relações trabalhistas: "A contratação do autônomo, cumpridas por este todas as formalidades legais, com ou sem exclusividade, de forma contínua ou não, afasta a qualidade de empregado prevista no art. $3^{\circ}$ desta Consolidação."

É mais do que pejotização, o trabalhador não precisa se transformar em um Empresário Individual (EI) ou em uma Empresa Individual de Responsabilidade Limitada (EIRELI), o autônomo não precisa ter nem uma pessoa jurídica.

A Lei 8.213/91 quando enumera os beneficiários do Regime Geral de Previdência Social utiliza a expressão "trabalhador autônomo" e "equiparado a trabalhador autônomo" para descrever várias formas de trabalho. Entretanto, a reforma da previdência do Governo FHC de 1999 revogou essas expressões e passou a utilizar o termo "contribuinte individual".

\footnotetext{
13 Súmula 444 JORNADA DE TRABALHO. NORMA COLETIVA. LEI. ESCALA DE 12 POR 36. VALIDADE (Res. 185/2012) É valida, em caráter excepcional, a jornada de doze horas de trabalho por trinta e seis de descanso, prevista em lei ou ajustada exclusivamente mediante acordo coletivo de trabalho ou convenção coletiva de trabalho, assegurada a remuneração em dobro dos feriados trabalhados. O empregado não tem direito ao pagamento de adicional referente ao labor prestado na décima primeira e décima segunda horas.

14 OJ-SDI1 388 JORNADA 12X36. JORNADA MISTA QUE COMPREENDA A TOTALIDADE DO PERÍODO NOTURNO. ADICIONAL NOTURNO. DEVIDO. (DEJT 11.06.2010)

O empregado submetido à jornada de 12 horas de trabalho por 36 de descanso, que compreenda a totalidade do período noturno, tem direito ao adicional noturno, relativo às horas trabalhadas após as 5 horas da manhã.

15 Art. 59-A. Em exceção ao disposto no art. 59 desta Consolidação, é facultado às partes, mediante acordo individual escrito, convenção coletiva ou acordo coletivo de trabalho, estabelecer horário de trabalho de doze horas seguidas por trinta e seis horas ininterruptas de descanso, observados ou indenizados os intervalos para repouso e alimentação.

Parágrafo único. A remuneração mensal pactuada pelo horário previsto no caput deste artigo abrange os pagamentos devidos pelo descanso semanal remunerado e pelo descanso em feriados, e serão considerados compensados os feriados e as prorrogações de trabalho noturno, quando houver, de que tratam o art. 70 e o $₫ 5^{\circ}$ do art. 73 desta Consolidação.
} 
O trabalhador autônomo trazia a ideia de prestação de serviço em caráter eventual. Entretanto, o art. 442-B fala que a contratação pode ser feita "de forma contínua ou não", "com ou sem exclusividade", abrindo infinitas possibilidades. O que é um autônomo exclusivo contratado de forma contínua? Qual o limite que impede uma empresa de contratar toda a sua mão de obra como autônomos, remunerando a todos por meio de Recibo de Pagamento ao Contribuinte Individual (RPCI)?

\subsubsection{Contrato de trabalho intermitente}

A principal novidade dessa reforma é o trabalho intermitente.

O contrato de trabalho intermitente criado pelo art. 452-A é uma modalidade ultra flexível de jornada de trabalho chamada em outros países de contrato zero hora e limitada para algumas atividades. Entretanto, o contrato de trabalho intermitente foi incluído na CLT sem nenhuma restrição. ${ }^{16}$ Pela redação aprovada, qualquer trabalhador em qualquer setor (exceto os aeronautas, art. $443, \int 3^{\circ}$ ) pode ser contratado por hora, e o período de inatividade pode ser de horas, dias ou meses. Da forma como está, sem a possibilidade de limitação dessa modalidade contratual por conta da retirada de poder da Justiça do Trabalho, todos os trabalhadores brasileiros poderiam ser inseridos nesse tipo de contrato. Assim, com a possibilidade de migração de todos os empregados para contratos de trabalho intermitente, bem como pela possibilidade de contratar um autônomo exclusivo de forma contínua, como visto anteriormente, toda a CLT passa a carecer de sentido, transformando-se em um entulho normativo.

\footnotetext{
16 "Art. 452-A. O contrato de trabalho intermitente deve ser celebrado por escrito e deve conter especificamente o valor da hora de trabalho, que não pode ser inferior ao valor horário do salário mínimo ou àquele devido aos demais empregados do estabelecimento que exerçam a mesma função em contrato intermitente ou não.

$\mathbb{S} 1^{\circ} \mathrm{O}$ empregador convocará, por qualquer meio de comunicação eficaz, para a prestação de serviços, informando qual será a jornada, com, pelo menos, três dias corridos de antecedência.

$\int 2^{\circ}$ Recebida a convocação, o empregado terá o prazo de um dia útil para responder ao chamado, presumindo-se, no silêncio, a recusa.

$\int 3^{\circ}$ A recusa da oferta não descaracteriza a subordinação para fins do contrato de trabalho intermitente.

$\int 4^{\circ}$ Aceita a oferta para o comparecimento ao trabalho, a parte que descumprir, sem justo motivo, pagará à outra parte, no prazo de trinta dias, multa de $50 \%$ (cinquenta por cento) da remuneração que seria devida, permitida a compensação em igual prazo.

$\int 5^{\circ} \mathrm{O}$ período de inatividade não será considerado tempo à disposição do empregador, podendo o trabalhador prestar serviços a outros contratantes.

$\llbracket 6^{\circ}$ Ao final de cada período de prestação de serviço, o empregado receberá o pagamento imediato das seguintes parcelas:

I - remuneração;

II - férias proporcionais com acréscimo de um terço;

III - décimo terceiro salário proporcional;

IV - repouso semanal remunerado; e

$\mathrm{V}$ - adicionais legais.

$\int 7^{\circ} \bigcirc$ recibo de pagamento deverá conter a discriminação dos valores pagos relativos a cada uma das parcelas referidas no $\$$ $6^{\circ}$ deste artigo.

$\int 8^{\circ} \mathrm{O}$ empregador efetuará o recolhimento da contribuição previdenciária e o depósito do Fundo de Garantia do Tempo de Serviço, na forma da lei, com base nos valores pagos no período mensal e fornecerá ao empregado comprovante do cumprimento dessas obrigações.

$\int 9^{\circ}$ A cada doze meses, o empregado adquire direito a usufruir, nos doze meses subsequentes, um mês de férias, período no qual não poderá ser convocado para prestar serviços pelo mesmo empregador."
} 
O deputado Rogério Marinho (PSDB/RN) alega que o contrato intermitente terá impacto direto na criação de empregos, mas não discute a qualidade desses empregos e muito menos quantos contratos atuais poderão migrar para essa modalidade de contratação. Na discussão da terceirização, impediu-se que o empregado demitido preste serviço para a empresa que o demitiu nos 18 meses seguintes. Entretanto, essa vedação não existe para o contrato intermitente, aparentemente muito mais vantajoso do que a terceirização, tampouco para a contratação do autônomo exclusivo de forma contínua.

No Senado, a única forma de aprovar essa modalidade contratual foi acenar com o veto do dispositivo pelo Presidente da República ou com a edição de Medida Provisória. $\bigcirc$ argumento do senador Ricardo Ferraço (PSDB/ES) foi para que os senadores aprovassem, para depois o Executivo vetar ou alterar. Os senadores aprovaram, o veto não veio e, até 20 de agosto, a Medida Provisória não foi editada.

Sem dúvida, uma das principais inovações desta proposta é a criação do trabalho intermitente, feita pelos arts. 443 e 452-A da CLT, na forma do projeto. Não concordamos com os argumentos colecionados pelos opositores da proposta de que ela transfere o risco da atividade econômica da empresa para o empregador, violando a função social da propriedade prevista na Constituição e tratando o trabalhador como um insumo qualquer. Pelo contrário, esta é uma medida destinada a reduzir nossos altos índices de rotatividade e a permitir a inclusão no mercado de trabalho de jovens, mulheres e idosos, que têm maior dificuldade de cumprir a jornada "cheia".

Entretanto, é necessária cautela. Esta mudança tem que ser feita de maneira segura, e não drástica. Futura medida provisória deve conceder salvaguardas necessárias para o trabalhador e talvez delimitar setores em que este tipo de jornada vai ser permitida. Muito embora acreditemos que a realidade de diversos setores da economia não se enquadra na lógica do trabalho intermitente, esta regulação não pode ser deixada para ser feita isoladamente pelo mercado. Temos de reconhecer que há enorme desigualdade no grau de maturidade das relações de trabalho pelo País, e que permitir o trabalho intermitente de qualquer forma pode levar a abusos e à precarização.

Portanto, recomendamos o veto e a edição de medida provisória tratando deste item. (FERRAÇO, 2017, grifo nosso).

\subsubsection{Ampliação da terceirização}

A possibilidade indiscriminada do contrato de trabalho intermitente e da contratação dos autônomos exclusivos de forma continuada retira boa parte do interesse econômico e da relevância da discussão sobre a terceirização. Contratar alguém por horas avulsas ou um autônomo pode ser muito mais vantajoso economicamente do que contratar uma empresa terceirizadora de mão de obra. Além disso, para que não restem dúvidas sobre os interesses precarizantes das relações de trabalho, a Lei 6.019/1974, que tinha acabado de ser reformada em março de 2017 para incluir a terceirização na legislação trabalhista, é reformada novamente para não deixar nenhuma dúvida de que a possibilidade de terceirização é ampla, geral e irrestrita. 
O art. 4º-A foi criado em março de 2017 com a seguinte redação: "Empresa prestadora de serviços a terceiros é a pessoa jurídica de direito privado destinada a prestar à contratante serviços determinados e específicos." Apenas três meses depois, a reforma trabalhista o substitui pelo seguinte: "Considera-se prestação de serviços a terceiros a transferência feita pela contratante da execução de quaisquer de suas atividades, inclusive sua atividade principal, à pessoa jurídica de direito privado prestadora de serviços que possua capacidade econômica compatível com a sua execução."

\subsubsection{Teletrabalho}

O teletrabalho ganhou um capítulo próprio, sendo incluído no Título II, "Normas Gerais de Tutela do Trabalho" o Capítulo II-A com cinco artigos (art. 75-A a art. 75-E). Enfim, a "modernidade" adentra a CLT: "Em uma tentativa de colocar o nosso País entre as nações mais modernas do mundo, estamos propondo a regulamentação de alguns desses 'novos' modelos de contratação, os quais, diga-se, já deveriam estar sendo adotados há muito." (MARINHO, 2017, p. 40). Segundo o relator, o teletrabalhador terá flexibilidade para gerenciar o seu tempo, bem como mais tempo de convivência com a família e aumentará a sua produtividade.

O deputado potiguar alega que a regulação aumentará o número de pessoas no mercado de trabalho formal e regularizará os mais de quatro milhões de brasileiros que trabalham nessa condição como autônomos. $\bigcirc$ que é algo extremamente curioso, a mesma reforma trabalhista que permitiu a contratação de autônomos acha que a regulação do teletrabalho permitirá a transformação dos atuais autônomos em futuros celetistas. Se a própria reforma está permitindo e legalizando a contratação de autônomos sem vínculo trabalhista, qual a vantagem para a empresa que já utiliza o teletrabalho de autônomos convertê-los em celetistas?

Por fim, Rogério Marinho (PSDB/RN) apela a questões ambientais para a regulação do trabalho à distância afirmando que sua aplicação diminuirá o número de carros nas cidades, trazendo inegáveis impactos positivos para o empregador, o empregado e a sociedade e trazendo mais qualidade de vida para as pessoas. Tudo isso são vantagens das atuais modificações tecnológicas:

diante da alta conectividade e dos recursos que permitem o acesso remoto e seguro aos dados empresariais, sendo possível o envio de e-mails, o acesso de arquivos que se encontrem na empresa, a realização de reuniões por teleconferência, ou seja, instrumentos suficientes para que o trabalho seja realizado sem quaisquer comprometimentos. (MARINHO, 2017, p. 41).

\subsubsection{Trabalho insalubre da mulher gestante ou lactante}

A Lei 13.287, de 11 de maio de 2016, tinha acabado de incluir na CLT o art. 394-A com a seguinte redação: "A empregada gestante ou lactante será afastada, enquanto durar a gestação e a 
lactação, de quaisquer atividades, operações ou locais insalubres, devendo exercer suas atividades em local salubre."

Impedir que uma mulher gestante ou lactante trabalhe em um lugar insalubre é uma conquista mínima, elementar, básica de qualquer esforço civilizatório.

A reforma trabalhista inverteu a redação do artigo incluído na CLT, há pouco mais de um ano, para permitir que gestantes e lactantes trabalhem em lugares insalubres.

Como o impacto dessa norma não é muito significativo no custo da mão de obra, aprovar o trabalho insalubre da mulher gestante ou lactante soa como uma demonstração de força desnecessária para sinalizar que este Congresso é capaz das medidas mais abjetas. Vale lembrar que a lei que proibia o trabalho insalubre foi uma das últimas assinadas por uma mulher que se autodenominava presidenta.

O senador Ferraço, no relatório da CAE do Senado, rejeitou todas as emendas que tentavam proteger mulheres grávidas de condições degradantes, com a promessa de veto (que não ocorreu) e regulamentação posterior (que ainda não veio).

\subsection{Modificação da estrutura sindical}

A Constituição de 1988 tentou conjugar a liberdade sindical, "é livre a associação profissional ou sindical", com a unicidade, "é vedada a criação de mais de uma organização [...] na mesma base territorial."

Foi a atuação dos órgãos de registro e a contribuição sindical que definiram o desenho dos sindicatos após a redemocratização. Até a Portaria MTE 343, de 04 de maio de 2000, bastava o registro do sindicado em cartório para a sua criação. Os sindicatos concorrentes iniciavam na justiça do trabalho disputas em torno do reconhecimento e da contribuição. Em 2002, o TST devolve ao Ministério do Trabalho a prerrogativa de reconhecimento dos sindicatos, o que é reforçado em $2008 \mathrm{com}$ a inclusão das centrais sindicais na partilha da contribuição. Isso gerou um cenário de fragmentação sindical e de eleições sindicais concorridas (estimuladas pelas disputas entre as centrais).

O Brasil tem 11.240 organizações representativas de trabalhadores e 5.251 organizações de empregadores, sendo 15.892 sindicatos, 549 federações, 43 confederações e sete centrais sindicais (CAMPOS, 2016, p. 9-10).

Se o pressuposto da reforma, expresso nas discussões do Congresso, fosse realmente o de permitir a regulação das relações de trabalho mais pelo negociado do que pelo legislado, a primeira etapa de uma reforma trabalhista seria a reforma sindical e a criação de condições de representação adequada para que os trabalhadores possam verdadeiramente negociar as normas de seu contrato. Entretanto, a reforma trabalhista, além de não desenhar uma nova estrutura sindical, apenas enfraquece a existente, a partir de duas medidas fundamentais, extinguindo o imposto sindical e criando uma representação dos empregados nas empresas, desvinculada da estrutura sindical, além de outras 
pequenas alterações, como, por exemplo, a retirada da obrigatoriedade de homologação da rescisão pelo sindicato (revogação do $\int 1^{\circ}$ do art. 477).

É uma meia verdade a afirmação do deputado Rogério Marinho (PSDB/RN) de que nossa estrutura sindical é a mesma dos anos 1930 e que é, portanto, fascista. ${ }^{17} \mathrm{O}$ movimento sindical dos anos 1970 tentou romper com a estrutura sindical anterior, contribuiu com o fim da Ditadura Militar, teve participação política ativa e central na redemocratização, serviu de base para a construção de partidos políticos, e de seus quadros saiu um presidente da República.

O Governo Temer recuperou o discurso da imprescindível reforma trabalhista do Governo FHC. Se nos anos 1990 imaginava-se que o sindicalismo tinha perdido força social e política, o século XXI inicia-se com 13 anos de governo do partido nascido no movimento sindical e de importantes dirigentes sindicais assumindo posições-chave na estrutura estatal brasileira.

É preciso lembrar que o Governo Lula, no início, anunciava as reformas sindical e trabalhista com uma das suas prioridades. Para realizá-las criou, no Ministério do Trabalho, o Fórum Nacional do Trabalho, que apresentou uma série de propostas de reformas, mas não logrou nenhum avanço significativo. Em maio de 2006, em razão do fracasso do Fórum, o Governo edita uma Medida Provisória criando o Conselho Nacional de Relações do Trabalho cuja finalidade seria "promover o entendimento entre trabalhadores, empregadores e Governo Federal, buscando soluções acordadas sobre temas relativos às relações do trabalho e à organização sindical." (art. 2ª inciso I da MP 294). Essa Medida Provisória foi rejeitada em setembro de 2006, e o único resultado significativo de toda essa discussão foi a Lei 11.648, de 31 de março de 2008, que reconheceu as centrais sindicais e definiu a parte que lhes cabe da contribuição sindical. As propostas do Fórum Nacional do Trabalho foram duramente criticadas por Ricardo Antunes. ${ }^{18}$

Até a tomada do poder pelo Governo Temer as reformas trabalhista e sindical saem de pauta. De 2007 a 2009 tramitou na Câmara dos Deputados um projeto de lei para uma nova CLT. ${ }^{19}$ Discutiu-se a ratificação da Convenção 158 da OIT que impediria a demissão sem justa causa. Ten-

\footnotetext{
17 "É fato que o modelo sindical adotado no País ainda é praticamente o mesmo da época de sua criação, no período conhecido como Estado Novo, em que vivíamos a ditadura do governo Vargas.

Criada em uma época em que as garantias constitucionais estavam suspensas, a contribuição sindical tem inspiração claramente fascista, uma vez que tinha como principal objetivo subsidiar financeiramente os sindicatos para que dessem sustentação ao governo." (MARINHO, 2017, p. 58).

18 "[...] por que o governo Lula optou pelo uso do dualismo getulista, isto é, dividir a reforma em sua face sindical e trabalhista? Nossa resposta é mais hipotética que conclusiva: talvez isso se deva à necessidade de recuperar forças, depois do enorme desgaste social sofrido pelo governo entre os assalariados públicos e seu sindicalismo mais combativo, a partir do desmonte (privatista e anti-social) da previdência pública. Agora o desmonte vai atingir a totalidade da classe trabalhadora, não só seu contingente público, mas especialmente o universo privado." (ANTUNES, 2006, p. 503).

"O dualismo lulista foi, então, o caminho escolhido para enterrar o que ainda se mantém do dualismo getulista. É o artífice usando o feitiço contra o feiticeiro. Se cabe ao governo Lula fazer mais esta reforma, nossa conclusão não pode ser outra: triste o país em que um governo comandado por um estancieiro criou, sob pressão operária, a nossa legislação social e trabalhista e, agora, mais de sessenta anos depois, um artífice da metalurgia, sob pressão burguesa, encontra-se servilmente disposto a destruí-la. Completando, também nesse quesito 'pouco nobre', o trabalho começado pelo príncipe." (ANTUNES, 2006, p. 508). 19 Projeto de Lei n. 1.987, de 06 de setembro de 2007. Autoria de Cândido Vaccarezza (PT/SP). Arquivado em 31 de janeiro de 2015.
} 
tou-se criar um fundo garantidor das execuções trabalhistas. Ampliou-se enormemente o poder e a influência do judiciário trabalhista.

Adalberto Cardoso, analisando a crise do sindicalismo em 2015, entende que as vitórias do sindicalismo no início deste século, por ocorrerem em um presidencialismo de coalisão, não permitiram a implantação da agenda política do movimento sindical (CARDOSO, 2015, p. 507).

Entretanto, com a derrubada do Governo Dilma, cai o projeto político do qual participaram ativamente os sindicatos e os políticos deles oriundos. É significativa a desconsideração do relatório do senador Paim no Senado. Essa reforma trabalhista foi feita por deputados pastores, senadores empresários e políticos da Ditadura Militar, a única voz dissonante é a do senador sindicalista do partido abatido do poder.

O mais duro golpe na estrutura sindical foi sem dúvida a modificação do art. 545, que eliminou a contribuição sindical obrigatória. Acusada pelo deputado do PSDB, relator da Câmara, por sua alegada inspiração fascista, pela formação de sindicatos de sustentação política do governo, contrária ao princípio da liberdade sindical:

Os fundamentos da época em que a contribuição sindical foi criada não mais subsistem e o seu caráter obrigatório é um verdadeiro contrassenso com o princípio da liberdade sindical, consagrado em nossa Constituição. Não se pode admitir que a contribuição sindical seja imposta a todos os integrantes das categorias econômicas e profissionais e, ao mesmo tempo, que a Carta Magna determine que ninguém é obrigado a se filiar ou se manter filiado a entidade sindical.

$[\ldots]$

As entidades sindicais terão que se mostrar efetivas em suas atuações, atendendo os anseios de seus representados, para que eles decidam livremente pelo suporte financeiro das atividades. Não há justificação para se exigir a cobrança de uma contribuição de alguém que não é filiado e que, muitas vezes, discorda frontalmente da atuação de seu sindicato.

E essa contrariedade à forma de atuar dos sindicatos explica, em grande medida, a inexpressiva taxa de sindicalização no Brasil. Apenas algo em torno de $20 \%$ dos trabalhadores brasileiros são filiados a alguma entidade sindical, segundo dados do próprio Ministério do Trabalho.

Temos uma firme convicção de que o fortalecimento da estrutura sindical brasileira passa pelo fim da contribuição sindical impositiva, que acaba por estimular a criação de sindicatos sem qualquer representatividade, apenas com a finalidade de arrecadar esse "tributo". (MARINHO, 2017, p. 58-59).

Entretanto, em nenhum momento se discutiram as contribuições para o Sistema S, primo-irmão da contribuição sindical.

Ao mesmo tempo em que se retira a principal fonte de financiamento da estrutura sindical, tenta-se criar uma nova forma de representação trabalhista "assindical".

A Constituição previu no art. 11 a criação, em empresas com mais de 200 empregados, de representação eleita por eles. O principal objetivo do projeto original do Governo Temer era regulamentar essa representação dos trabalhadores. A Lei aprovada ampliou a proposta do projeto criando um título próprio na CLT e os artigos 510-A a 510-E. Entretanto, a "comissão de representantes dos empregados" (formada por três a sete trabalhadores) foi estruturada de forma completamente sepa- 
rada da existente estrutura sindical, é uma representação "assindical". O \ $1^{\circ}$ do art. 510-C proíbe expressamente a interferência do sindicato da categoria no processo eleitoral da comissão. Os trabalhadores integrantes da comissão de representantes não poderão ser reeleitos por dois mandatos seguintes aos seus e não podem "sofrer despedida arbitrária" do registro da candidatura até um ano após o fim do mandato de um ano.

\section{Considerações finais}

Em 29 de outubro de 2015, o presidente da Câmara, Eduardo Cunha (PMDB/RJ), manobrava para alterar o rito de votação do impedimento da presidente Dilma, e o vice-presidente Temer, junto com o seu partido, lançava um manifesto intitulado Uma ponte para o futuro.

A coalizão PMDB-PT era claramente rompida, e o PMDB apresentava um novo programa de governo diametralmente oposto ao aprovado nas eleições do ano anterior. $O$ item i do novo projeto de governo propunha "na área trabalhista, permitir que as convenções coletivas prevaleçam sobre as normas legais, salvo quanto aos direitos básicos." (PMDB; FUNDAÇÃO ULYSSES GUIMARÃES, 2015, p. 19), mas o foco da proposta era a reforma da previdência, tema complexo, tratado de forma simplória: "as causas destes problemas são simples: as pessoas estão vivendo mais e as taxas de novos entrantes na população ativa são cada vez menores." (PMDB; FUNDAÇÃO ULYSSES GUIMARÃES, 2015, p. 11). A solução proposta era igualmente simples: "ampliar a idade mínima para a aposentadoria, de sorte que as pessoas passem mais tempo de suas vidas trabalhando e contribuindo, e menos tempo aposentados." (PMDB; FUNDAÇÃO ULYSSES GUIMARÃES, 2015, p. 11).

O Governo Temer não foi eleito e, portanto, não teve um programa apresentado e debatido de forma democrática, mas o seu projeto está claramente enunciado no manifesto de outubro de 2015. Um programa que talvez dificilmente seria sufragado pelo povo, mas que está sendo cumprido religiosamente por um Congresso participante da nova coalisão. A aprovação de uma reforma trabalhista tão ampla e em tão pouco tempo mostra tanto a força e a eficiência do Governo Temer em manter disciplinado o Congresso utilizando todos os meios tradicionais da política brasileira (de liberação de emendas à distribuição de cargos), quanto a relação de identidade entre o Congresso e um governo quase parlamentar. $\bigcirc$ Governo Temer é a tomada do Poder Executivo pelo Poder Legislativo e nasceu de um processo de impeachment cuja peça central foi o presidente da Câmara dos Deputados (preso desde outubro de 2016); o próprio Temer foi duas vezes presidente da Câmara dos Deputados, e todos os principais ministros por ele escolhidos têm a característica de serem políticos exímios conhecedores do funcionamento do Congresso. ${ }^{20}$

20 Talvez o ministro do governo Temer mais representativo da origem parlamentar do seu governo seja Henrique Eduardo
Alves (PMDB/RN), que foi deputado federal com 11 (onze) mandatos consecutivos permanecendo na Câmara de 1971 até
2015, preso desde junho de 2017. Além dele, Geddel Vieira Lima (PMDB/BA), Ministro da Secretaria de Governo da Presi-
dência da República, foi deputado federal de 1991 a 2007 ( 5 mandatos consecutivos), preso em julho de 2017. Eliseu Padilha
(PMDB/RS), Ministro-Chefe da Casa Civil, foi deputado federal de 1995 a 2015. Moreira Franco (PMDB/RJ), Ministro-Chefe 
A reforma trabalhista, e sua rápida tramitação, é apenas um exemplo da forma de relacionamento do Governo Temer com o Congresso e da eficiência da nova coalisão em impor sua pauta ao País.

\section{Referências}

ANTUNES, Ricardo (Org.). Riqueza e miséria do trabalho no Brasil. São Paulo: Boitempo, 2006.

CÂMARA DOS DEPUTADOS. Deputado Ronaldo Nogueira. Disponível em: ‘www.camara.leg.br/ internet/deputado/dep_Detalhe.asp?.id =5830723>Ace sso em: 10 ago. 2017.

CÂMARA DOS DEPUTADOS. Frente Parlamentar Evangélica do Congresso Nacional. 09 nov. 2015. Disponível em: ${ }^{<} w w w . c a m a r a . l e g . b r / i n t e r n e t / d e p u t a d o / f r e n t e D e t a l h e . a s p ? . i d=53658>$. Ace ${ }^{\text {Sso }} \mathrm{em}$ : 10 ago. 2017.

CAMPOS, André Gambier. Sindicatos no Brasil: o que esperar no futuro próximo? Texto para discussão n. 2262. Brasília: IPEA, dez. 2016.

CARDOSO, Adalberto Moreira. Dimensões da crise do sindicalismo brasileiro. Caderno CRH, Salvador, v. 28, n. 75, p. 493-510, set./dez. 2015.

DIEESE. A Reforma Trabalhista e os impactos para as relações de trabalho no Brasil. São Paulo: DIEESE, maio 2017. (Nota Técnica, 178).

DIEESE. Relações de trabalho sem proteção: de volta ao período anterior a 1930. São Paulo: DIEESE, maio 2017. (Nota Técnica, 179).

DIEESE. Riscos e perdas impostos pelo PL 6.787/2016 aos trabalhadores e ao movimento sindical. DIEESE, maio 2017. (Texto-síntese).

FERRAÇO, Ricardo. Parecer (SF) n 34, de 2017. Comissão de Assuntos Econômicos, sobre o processo Projeto de Lei da Câmara n 38, de 2017, que Altera a Consolidação das Leis do Trabalho (CLT), aprovada pelo Decreto-Lei n ${ }^{\circ} 5.452$, de $1^{\circ}$ de maio de 1943, e as Leis $n^{\circ s} 6.019$, de 3 de janeiro de 1974, 8.036, de 11 de maio de 1990, e 8.212, de 24 de julho de 1991, a fim de adequar a legislação às novas relações de trabalho. Brasília, DF, 2017. Disponível em: <http://legis.senado.leg.br/sdleg-getter/documento? $\mathrm{dm}=5302372 \&$ disposition $=$ inline $>$. Acesso em: 15 ago. 2017.

JUCÁ, Romero. Parecer (SF) no 67, de 2017. Comissão de Constituição, Justiça e Cidadania, sobre o processo Projeto de Lei da Câmara ${ }^{\circ} 38$, de 2017, que Altera a Consolidação das Leis do TrabaIho (CLT), aprovada pelo Decreto-Lei n ${ }^{\circ} 5.452$, de $1^{\circ}$ de maio de 1943, e as Leis nos 6.019 , de 3 de janeiro de 1974, 8.036, de 11 de maio de 1990, e 8.212, de 24 de julho de 1991, a fim de adequar a legislação às novas relações de trabalho. Brasília, DF, 2017. Disponível em: <http://legis.senado.leg. br/sdleg-getter/documento? $\mathrm{dm}=5375790 \&$ disposition=inline > . Acesso em: 12 ago. 2017.

da Secretaria-Geral da Presidência, foi deputado federal de 1977 a 1982, de 1995 a 2007, governador do Rio de Janeiro (1987 a 1991), e é sogro do atual presidente da Câmara dos Deputados, Rodrigo Maia (DEM/RJ). Romero Jucá (PMDB/RR), com três mandatos de senador deixou o ministério por conta de denúncias de corrupção para assumir a liderança do governo no Senado e foi um dos principais articuladores da reforma trabalhista. Bem como, um dos autores da terceirização, Sandro Mabel (PMDB/GO), deputado federal de 1995 a 201, Assessor Especial de Michel Temer que pediu demissão por conta de denúncias de corrupção em maio de 2017. 
MARINHO, Rogério Simonetti. PRL 2 PL678716. Relatório apresentado à Comissão especial destinada a proferir parecer ao Projeto de Lei $n^{\circ}$ 6.787, de 2016, do Poder Executivo, que "altera o Decreto-Lei n ${ }^{\circ} 5.452$, de $1^{\circ}$ de maio de 1943 - Consolidação das Leis do Trabalho, e a Lei n 6.019 , de 3 de janeiro de 1974, para dispor sobre eleições de representantes dos trabalhadores no local de trabalho e sobre trabalho temporário, e dá outras providências. Brasília, DF, 2017. Disponível em: $<w w w . c a m a r a . g o v . b r /$ proposicoesWeb/fichadetramitacao? idProposicao $=2130974>$. Acesso em: 11 ago. 2017.

PAIM, Paulo. Parecer (SF) no 29, de 2017. Comissão de Assuntos Sociais, sobre o processo Projeto de Lei da Câmara $n^{\circ} 38$, de 2017, que Altera a Consolidação das Leis do Trabalho (CLT), aprovada pelo Decreto-Lei $n^{0} 5.452$, de $1^{\circ}$ de maio de 1943 , e as Leis $n^{\text {os }} 6.019$, de 3 de janeiro de 1974, 8.036, de 11 de maio de 1990, e 8.212, de 24 de julho de 1991, a fim de adequar a legislação às novas relações de trabalho. Brasília, DF, 2017. Disponível em: <http://legis.senado.leg.br/sdleg-getter/documento? $\mathrm{dm}=5349695 \&$ disposition $=$ inline $>$. Acesso em: 12 ago. 2017 .

PMDB; FUNDAÇÃO ULYSSES GUIMARÃES. Uma ponte para o futuro. Brasília, DF, 29 out. 2015. Disponível em: <http://pmdb.org.br/wp-content/uploads/2015/10/RELEASE-TEMER_A4-28.10. 15-Online.pdf>. Acesso em: 12 ago. 2017.

Data da submissão: 24 de agosto de 2017 Aceito em: 24 de agosto de 2017 
